\title{
Dual burden of body weight among Iranian children and adolescents in 2003 and 2010: the CASPIAN-III study
}

\author{
Masoud Rahmanian ${ }^{1}$, Roya Kelishadi², Mostafa Qorbani ${ }^{3,4}$, Mohammad Esmaeil Motlagh", \\ Gita Shafiee ${ }^{7,8}$, Tahereh Aminaee ${ }^{6}$, Gelayol Ardalan ${ }^{6}$, Mahnaz Taslimi $^{9}$, Parinaz Poursafa ${ }^{2}$, \\ Hamid Asayesh ${ }^{10}$, Bagher Larijani ${ }^{8}$, Ramin Heshmat ${ }^{7,8}$
}

${ }^{1}$ Yazd Diabetes Research Center, Shahid Sadoughi University of Medical Sciences, Yazd, Iran

${ }^{2}$ Department of Pediatrics, Child Growth and Development Research Center, Isfahan University of Medical Sciences, Isfahan, Iran

${ }^{3}$ Department of Public Health, Alborz University of Medical Sciences, Karaj, Iran ${ }^{4}$ Department of Epidemiology, Iran University of Medical Sciences, Tehran, Iran

${ }^{5}$ Department of Pediatrics, Ahvaz Jundishapur University of Medical Sciences, Ahvaz, Iran

${ }^{6}$ Bureau of Population, Family and School Health, Ministry of Health and

Medical Education, Tehran, Iran

${ }^{7}$ Chronic Diseases Research Center (CDRC), Endocrinology and Metabolism

Population Sciences Institute, Tehran University of Medical Sciences, Tehran, Iran

${ }^{8}$ Research Center, Endocrinology and Metabolism Research Institute,

Tehran University of Medical Sciences, Tehran, Iran

${ }^{9}$ Bureau of Health and Fitness, Ministry of Education and Training, Tehran, Iran

${ }^{10}$ Department of Medical Emergencies, Qom University of Medical Sciences, Qom, Iran

Submitted: 14 June 2012

Accepted: 25 March 2013

Arch Med Sci 2014; 10, 1: 96-103

DOI: 10.5114/aoms.2014.40735

Copyright @ 2014 Termedia \& Banach

\section{Abstract}

Introduction: Our aim was to compare changes of body mass index (BMI) and waist circumference (WC) curves of Iranian children by comparing the results of two national surveys of a surveillance program, i.e. CASPIAN-I (20032004) and CASPIAN-III (2009-2010). The second objective was to evaluate the prevalence of obesity, overweight and underweight among 10-18-yearold Iranian children and adolescents.

Material and methods: This study was performed among students who were selected by multistage random cluster sampling from urban and rural areas of 27 provinces of Iran, as part of a national survey of school student high risk behavior entitled CASPIAN-III, conducted in 2009-2010.

Results: We evaluated 5088 school students (50.2\% boys). In rural areas, underweight was more common in boys and overweight and obesity in girls. In urban areas underweight and obesity were more common in boys, whereas overweight was more common in girls. The highest prevalence of underweight $(23.5 \%)$ was seen in students aged 13 years and the lowest $(11.4 \%)$ in those aged 18 years. Underweight was significantly more common in rural than in urban areas $(22.1 \%$ vs. $15.8 \%$, respectively, $p<0.0001)$ and overweight/obesity was more common in urban than in rural areas. Compared with the findings in 2003-2004, the overall prevalence of elevated body mass index (16.6\%) including obesity (9.1\%) and overweight (7.5\%) as well as underweight (17.5\%) increased from 2003 to 2010.

Conclusions: In recent years, the double burden of nutritional disorders has increased among Iranian children and adolescents, especially in rural areas. This change may be related to epidemiologic transition, notably in terms of nutrition transition and rapid changes in lifestyle habits. This finding is an important issue for policy-makers for interventional preventive programs.

Key words: obesity, underweight, waist circumference, body mass index, pediatric age.
Corresponding author:

Ramin Heshmat

EMRC

Dr Shariati Hospital

North Karegar St

Tehran 14114, Iran

Phone: +982188220037

E-mail: rheshmat@tums.ac.ir 


\section{Introduction}

The incidence of obesity in developing countries has been increasing in recent years [1, 2]. According to the World Health Organization (WHO) estimates, it will become the major health problem by the year 2020 [3]. Childhood obesity is a significant risk factor for adult obesity [4], and has many short-term and long-term health impacts such as insulin resistance, hypertriglyceridemia [5], type 2 diabetes [6], microalbuminuria [7], hypertension [8], and even cancers [9]. Abdominal obesity and increased waist circumference as its surrogate marker $[10,11]$ are risk factors for diabetes, hypertension, hyperlipidemia and ischemic heart disease [12, 13].

Epidemiologic transition, notably in terms of nutrition transition and rapid changes in lifestyle, resulted in the increase in various types of nutritional disorders at the global level. For instance, the prevalence of obesity among Pakistani children aged $5-14$ years was 3\% in 1994 and rose to $5.7 \%$ in 2004, whereas the corresponding figure for underweight decreased from $29.7 \%$ to $27.3 \%$ in this period [14]. It shows that obesity has been increasing in recent years but underweight is still high. This condition is known as the dual burden of body weight $[15,16]$. Such a double burden of nutritional disorders is not limited to developing countries but also is seen in industrialized countries such as Spain [17], Italy [18] and France [19].

The general health status of Iranian children has improved considerably over the last decades; however, rapid lifestyle change, notably a tendency to consume snacks and fast foods with low nutritional value, is a threat to their health [20]. Regarding the rapid change of lifestyle in Iran, we compared the data of two national surveys of a surveillance program entitled "Childhood and Adolescence Surveillance and Preventlon of Adult Noncommunicable disease" CASPIAN-III study. Our objective was to compare changes of waist circumference (WC) and body mass oindex (BMI) curves with the first phase of this study [21, 22] conducted in 2003-2004 and the third survey in 2009-2010 [23]. The second objective was to compare the prevalence of obesity, overweight and underweight based on BMI cut-offs of WHO in Iranian children and adolescents aged $10-18$ years in 2003 and 2010.

\section{Material and methods}

The national survey of school student high-risk behavior (2009-2010) was conducted as the third survey of the school-based surveillance system entitled the CASPIAN-III study. We have previously described the methodology of this survey [23] and here we present it in brief.
This school-based nationwide health survey was conducted in Iran with cooperation of the Ministry of Health and Medical Education; the Ministry of Education and Training, Child Growth and Development Research Center, Isfahan University of Medical Sciences; and the Endocrinology and Metabolism Research Institute of Tehran University of Medical Sciences in Iran. The survey was performed among 5088 students aged 10-18 years who were selected by multistage random cluster sampling from urban and rural areas of 27 provinces of Iran. Eligible schools in our study were stratified according to the information bank of the Ministry of Education, and then they were selected randomly. In selected schools, students were also selected randomly and after a complete explanation of the study objectives and protocols for students and their parents, written informed consent was obtained from parents and oral assent from students, then sampling and examinations were begun. A team of trained health care professionals recorded information in a checklist and carried out the examinations under a standard protocol by using calibrated instruments. Based on a standard protocol [24], weight, height and WC were measured and BMI was calculated as weight $(\mathrm{kg})$ divided by height squared $\left(\mathrm{m}^{2}\right)$. Weight was measured to the nearest $200 \mathrm{~g}$ in barefoot and lightly dressed condition. The WC was measured to the nearest $0.5 \mathrm{~cm}$ at the end of expiration at the midpoint between the top of the iliac crest and the lowest rib in a standing position. Waist circumference and height were measured using a non-elastic tape.

We used the WHO growth curves to define BMI categories, i.e. underweight as sex-specific $\mathrm{BMI}<-2$ $z$-score, overweight as sex-specific BMI for age of $>+1 z$-score, and obesity as sex-specific BMI for $>+2$ z-score [25].

\section{Statistical analysis}

Findings on continuous variables were expressed as means \pm standard deviation (SD) and categorical data were expressed as percentage. The Student two-tailed $t$ test was applied to compare the mean differences of the variables according to both gender and age.

Statistical analysis was performed using the SPSS for Windows software (version 16.0, SPSS, Chicago, IL), and $p<0.05$ was considered as statistically significant.

\section{Results}

Data on 5088 children and adolescents (2556 boys and 2532 girls) with complete information were included in the current study. Table I pres- 
M. Rahmanian, R. Kelishadi, M. Qorbani, M.E. Motlagh, G. Shafiee, T. Aminaee, G. Ardalan, M. Taslimi, P. Poursafa, H. Asayesh, B. Larijani, R. Heshmat

Table I. Mean and standard deviations (SD) for weight, height, waist circumference and BMI for a nationally representative sample of Iranian children and adolescents: CASPIAN-III Study

\begin{tabular}{|c|c|c|c|c|c|}
\hline Age [years] & Number $(n)$ & Weight [kg] & Height $[\mathrm{cm}]$ & Waist $[\mathrm{cm}]$ & BMI $\left[\mathrm{kg} / \mathrm{m}^{2}\right]$ \\
\hline \multicolumn{6}{|l|}{ Girls } \\
\hline 10 & 57 & $29.00 \pm 7.02$ & $131.28 \pm 9.34$ & $58.05 \pm 6.23$ & $16.86 \pm 3.84$ \\
\hline 11 & 197 & $31.73 \pm 7.31$ & $137.55 \pm 8.53$ & $60.79 \pm 9.47$ & $16.68 \pm 3.00$ \\
\hline 12 & 372 & $35.95 \pm 9.31$ & $141.45 \pm 9.36$ & $62.62 \pm 9.15$ & $17.78 \pm 3.75$ \\
\hline 13 & 307 & $40.78 \pm 10.33$ & $147.96 \pm 9.62$ & $64.74 \pm 8.60$ & $18.55 \pm 3.90$ \\
\hline 14 & 284 & $46.58 \pm 11.18$ & $153.43 \pm 9.98$ & $67.41 \pm 8.81$ & $19.58 \pm 3.98$ \\
\hline 15 & 376 & $49.79 \pm 11.03$ & $156.09 \pm 8.79$ & $69.26 \pm 9.02$ & $20.32 \pm 4.14$ \\
\hline 16 & 283 & $52.68 \pm 11.61$ & $157.82 \pm 10.40$ & $71.05 \pm 9.32$ & $20.97 \pm 3.91$ \\
\hline 17 & 323 & $54.16 \pm 10.09$ & $159.19 \pm 5.96$ & $71.39 \pm 9.81$ & $21.36 \pm 3.70$ \\
\hline 18 & 338 & $54.60 \pm 9.67$ & $159.97 \pm 8.59$ & $70.93 \pm 7.97$ & $21.26 \pm 3.62$ \\
\hline \multicolumn{6}{|l|}{ Boys } \\
\hline 10 & 31 & $29.48 \pm 6.38$ & $133.45 \pm 7.53$ & $59.00 \pm 6.68$ & $16.44 \pm 2.56$ \\
\hline 11 & 161 & $31.70 \pm 7.60$ & $136.50 \pm 7.05$ & $61.10 \pm 7.93$ & $16.87 \pm 2.92$ \\
\hline 12 & 401 & $35.40 \pm 9.40$ & $141.11 \pm 9.92$ & $63.90 \pm 9.57$ & $17.55 \pm 3.47$ \\
\hline 13 & 348 & $38.34 \pm 10.87$ & $144.64 \pm 9.92$ & $66.4 \pm 11.80$ & $18.10 \pm 4.00$ \\
\hline 14 & 300 & $42.95 \pm 11.10$ & $150.96 \pm 13.19$ & $67.54 \pm 9.30$ & $18.49 \pm 3.61$ \\
\hline 15 & 325 & $48.98 \pm 12.06$ & $158.16 \pm 12.08$ & $70.05 \pm 10.57$ & $19.23 \pm 3.84$ \\
\hline 16 & 293 & $54.49 \pm 12.94$ & $163.68 \pm 13.84$ & $72.22 \pm 10.46$ & $19.87 \pm 3.81$ \\
\hline 17 & 385 & $60.75 \pm 14.38$ & $168.72 \pm 13.69$ & $74.93 \pm 11.01$ & $20.93 \pm 4.14$ \\
\hline 18 & 316 & $64.6 \pm 14.51$ & $172.58 \pm 11.86$ & $76.97 \pm 10.75$ & $21.51 \pm 4.02$ \\
\hline
\end{tabular}

$B M I-$ body mass index

ents the means and SD of anthropometric indexes by age and sex. It shows that at all ages, the mean WC was higher in boys than in girls. At all ages, except 11 and 18 years, the mean BMI was higher in girls than in boys. In both genders, WC had an escalating pattern by increasing age.

According to the WHO growth charts for BMI [26], of children and adolescents studied, $17.5 \%$ (15.0\% of girls and $20.0 \%$ of boys) were underweight, $65.9 \%$ ( $68.5 \%$ of girls and $63.4 \%$ of boys) were normal weight, and $16.6 \%$ were overweight or obese, consisting of $7.5 \%$ overweight $(8.5 \%$ of girls and $6.5 \%$ of boys) and $9.1 \%$ obese $(8.1 \%$ of girls and $10.0 \%$ of boys). It shows that while underweight and obesity both are more common in boys than girls, overweight is more common in girls than in boys.

Among students aged 10-18 years, 1582 (30.8\%) lived in rural areas and 3562 (69.2\%) in urban areas. In rural areas, underweight was more common in boys (26.8\% vs. $17.3 \%)$ and overweight (6.6\% vs. $3.2 \%)$ and obesity (7.0\% vs. $4.4 \%)$ in girls $(p<0.05)$. In urban areas underweight $(17.5 \%$ vs.
$14.2 \%)$ and obesity (12.2\% vs. $8.6 \%$ ) were more common in boys and overweight (9.2\% vs. $7.7 \%)$ was more common in girls $(p<0.05)$. The highest prevalence of underweight (23.5\%) was seen in students aged 13 years and the lowest (11.4\%) in those aged 18 years. Underweight was significantly more common in rural than in urban areas ( $22.1 \%$ vs. $15.8 \%$, respectively, $p<0.0001)$ and overweight/obesity was more common in urban than in rural areas.

Tables II and III show the values of BMI and WC percentiles at each age interval for boys and girls, respectively.

Comparisons with the percentiles provided by the CASPIAN-I study showed that after the age of 12 , the $5^{\text {th }}$ percentile curve for $\mathrm{BMI}$ is lower in CASPIAN-III for both genders; but the corresponding figures for WC were higher in this study. The $50^{\text {th }}$ percentile curves for BMI and WC were lower in our study than the CASPIAN-I study but in the age group over 13 years, the $95^{\text {th }}$ percentiles for $\mathrm{BMI}$ and WC were higher in the current study than the first survey. 
Table II. Age- and gender-specific percentiles of waist circumference: comparison of CASPIAN-I and CASPIAN-III findings

\begin{tabular}{|c|c|c|c|c|c|c|c|c|c|c|c|c|c|c|c|}
\hline \multirow{3}{*}{$\begin{array}{l}\text { Age } \\
\text { [years] }\end{array}$} & \multirow[t]{3}{*}{ Gender } & \multicolumn{2}{|c|}{$5^{\text {th }}$} & \multicolumn{2}{|c|}{$10^{\text {th }}$} & \multicolumn{2}{|c|}{$25^{\text {th }}$} & \multicolumn{2}{|c|}{$50^{\text {th }}$} & \multicolumn{2}{|c|}{$75^{\text {th }}$} & \multicolumn{2}{|c|}{$90^{\text {th }}$} & \multicolumn{2}{|c|}{$95^{\text {th }}$} \\
\hline & & \multicolumn{2}{|c|}{ CASPIAN } & \multicolumn{2}{|c|}{ CASPIAN } & \multicolumn{2}{|c|}{ CASPIAN } & \multicolumn{2}{|c|}{ CASPIAN } & \multicolumn{2}{|c|}{ CASPIAN } & \multicolumn{2}{|c|}{ CASPIAN } & \multicolumn{2}{|c|}{ CASPIAN } \\
\hline & & 1 & III & 1 & III & I & III & I & III & I & III & I & III & 1 & III \\
\hline \multirow[t]{2}{*}{10} & Girls & 50 & 51 & 52 & 51 & 56 & 53 & 60 & 57 & 65 & 62 & 71 & 68 & 75 & 70 \\
\hline & Boys & 51 & 51 & 52 & 52 & 56 & 54 & 60 & 58 & 64 & 62 & 72 & 68 & 76 & 78 \\
\hline \multirow[t]{2}{*}{11} & Girls & 51 & 52 & 54 & 53 & 58 & 55 & 62 & 59 & 67 & 63 & 74 & 70 & 75 & 68 \\
\hline & Boys & 52 & 52 & 54 & 53 & 57 & 56 & 62 & 59 & 68 & 65 & 75 & 73 & 80 & 78 \\
\hline \multirow[t]{2}{*}{12} & Girls & 53 & 52 & 56 & 53 & 60 & 56 & 65 & 61 & 70 & 66 & 78 & 75 & 82 & 80 \\
\hline & Boys & 53 & 53 & 56 & 55 & 59 & 57 & 64 & 61 & 70 & 68 & 79 & 77 & 83 & 84 \\
\hline \multirow[t]{2}{*}{13} & Girls & 52 & 53 & 57 & 55 & 61 & 58 & 66 & 64 & 72 & 70 & 78 & 77 & 82 & 80 \\
\hline & Boys & 53 & 54 & 56 & 55 & 61 & 58 & 65 & 63 & 71 & 72 & 80 & 85 & 86 & 90 \\
\hline \multirow[t]{2}{*}{14} & Girls & 57 & 57 & 60 & 58 & 63 & 61 & 68 & 66 & 72 & 72 & 79 & 80 & 83 & 85 \\
\hline & Boys & 57 & 58 & 60 & 58 & 63 & 61 & 68 & 65 & 74 & 71 & 81 & 82 & 88 & 85 \\
\hline \multirow[t]{2}{*}{15} & Girls & 57 & 58 & 59 & 59 & 63 & 63 & 68 & 68 & 73 & 74 & 80 & 82 & 85 & 88 \\
\hline & Boys & 54 & 58 & 59 & 60 & 64 & 63 & 69 & 67 & 75 & 75 & 83 & 85 & 89 & 93 \\
\hline \multirow[t]{2}{*}{16} & Girls & 57 & 59 & 60 & 60 & 64 & 64 & 68 & 69 & 73 & 76 & 80 & 84 & 83 & 91 \\
\hline & Boys & 57 & 59 & 61 & 61 & 66 & 65 & 71 & 70 & 77 & 78 & 84 & 86 & 90 & 93 \\
\hline \multirow[t]{2}{*}{17} & Girls & 58 & 60 & 60 & 61 & 64 & 64 & 69 & 70 & 74 & 76 & 80 & 84 & 83 & 91 \\
\hline & Boys & 57 & 61 & 61 & 63 & 66 & 68 & 71 & 72 & 78 & 80 & 86 & 91 & 92 & 97 \\
\hline \multirow[t]{2}{*}{18} & Girls & 60 & 60 & 61 & 62 & 64 & 65 & 70 & 70 & 76 & 76 & 83 & 81 & 86 & 85 \\
\hline & Boys & 52 & 62 & 60 & 65 & 66 & 69 & 72 & 75 & 79 & 84 & 85 & 93 & 91 & 99 \\
\hline
\end{tabular}

CASPIAN - Childhood and Adolescence Surveillance and Preventlon of Adult Noncommunicable disease

Table IV compares the age- and gender-specific mean of WC and BMI between CASPIAN-I and CASPIAN-III findings.

\section{Discussion}

This national study presents the prevalence of weight disorders, and the age- and gender-specific reference curves of WC and BMI for a representative sample of 10-18-year-old Iranian children and adolescents. It shows a high prevalence of both underweight and excess weight. Comparison with the first survey of the CASPIAN Study [24] shows that in the last 8 years, both overweight and underweight have increased among Iranian children and adolescents.

In this CASPIAN-III study, with increasing age, the WC curve tended to plateau in girls but not in boys. This presentation is also reported in other countries [27, 28], and probably is secondary to the earlier beginning of puberty in girls.

Comparing our results with CASPIAN-I [21] showed that weight disorders in terms of under- weight, overweight, and obesity are all increasing among Iranian children and adolescents. This problem is not limited to Iran but also is seen in some other developing countries such as Vietnam [16], Indonesia [29] and Guinea [30]. Another cross-sectional nationwide survey among 862,433 Iranian children at school entry [31] revealed a prevalence of $19.1 \%$ of underweight and $16.2 \%$ of overweight and obesity.

Our findings show that the prevalence of obesity and overweight among Iranian adolescents is higher than Indo-Asian children [14, 32], similar to that in China [33] and Japan [34], and far lower than in Spain [17], USA [33], and Italy [18]. However, the prevalence of underweight among Iranian adolescents is lower than Indo-Asian children [14], similar to Chinese, and higher than that in Brazil, USA [33] and Japan [34]. However, it should be acknowledged that these studies have been performed based on different definitions for overweight and underweight.

National surveys in different developing countries reveal that while underweight still persists, 
M. Rahmanian, R. Kelishadi, M. Qorbani, M.E. Motlagh, G. Shafiee, T. Aminaee, G. Ardalan, M. Taslimi, P. Poursafa, H. Asayesh, B. Larijani, R. Heshmat

Table III. Age- and gender-specific percentiles of BMI: comparison of CASPIAN-I and CASPIAN-III findings

\begin{tabular}{|c|c|c|c|c|c|c|c|c|c|c|c|c|c|c|c|}
\hline \multirow{3}{*}{$\begin{array}{l}\text { Age } \\
\text { [years] }\end{array}$} & \multirow{3}{*}{ Gender } & \multicolumn{2}{|c|}{$5^{\text {th }}$} & \multicolumn{2}{|c|}{$10^{\text {th }}$} & \multicolumn{2}{|c|}{$25^{\text {th }}$} & \multicolumn{2}{|c|}{$50^{\text {th }}$} & \multicolumn{2}{|c|}{$75^{\text {th }}$} & \multicolumn{2}{|c|}{$90^{\text {th }}$} & \multicolumn{2}{|c|}{$95^{\text {th }}$} \\
\hline & & \multicolumn{2}{|c|}{ CASPIAN } & \multicolumn{2}{|c|}{ CASPIAN } & \multicolumn{2}{|c|}{ CASPIAN } & \multicolumn{2}{|c|}{ CASPIAN } & \multicolumn{2}{|c|}{ CASPIAN } & \multicolumn{2}{|c|}{ CASPIAN } & \multicolumn{2}{|c|}{ CASPIAN } \\
\hline & & I & III & I & III & I & III & I & III & I & III & I & III & I & III \\
\hline \multirow[t]{2}{*}{10} & Girls & 13 & 13 & 13 & 14 & 15 & 14 & 16 & 16 & 18 & 18 & 20 & 21 & 23 & 24 \\
\hline & Boys & 13 & 14 & 14 & 14 & 15 & 15 & 16 & 16 & 18 & 17 & 20 & 20 & 24 & 24 \\
\hline \multirow[t]{2}{*}{11} & Girls & 13 & 13 & 14 & 13 & 15 & 14 & 17 & 16 & 19 & 18 & 21 & 20 & 24 & 23 \\
\hline & Boys & 14 & 13 & 14 & 14 & 15 & 15 & 16 & 16 & 19 & 18 & 20 & 20 & 24 & 23 \\
\hline \multirow[t]{2}{*}{12} & Girls & 14 & 13 & 15 & 14 & 16 & 15 & 18 & 17 & 21 & 20 & 22 & 23 & 26 & 25 \\
\hline & Boys & 14 & 14 & 14 & 14 & 16 & 15 & 17 & 16 & 20 & 19 & 22 & 23 & 25 & 25 \\
\hline \multirow[t]{2}{*}{13} & Girls & 15 & 14 & 15 & 14 & 17 & 16 & 19 & 18 & 21 & 21 & 23 & 24 & 26 & 26 \\
\hline & Boys & 14 & 13 & 15 & 14 & 16 & 15 & 18 & 17 & 20 & 20 & 21 & 24 & 25 & 26 \\
\hline \multirow[t]{2}{*}{14} & Girls & 15 & 15 & 16 & 16 & 18 & 17 & 20 & 19 & 22 & 22 & 24 & 25 & 27 & 27 \\
\hline & Boys & 15 & 14 & 16 & 15 & 17 & 16 & 19 & 18 & 21 & 20 & 22 & 24 & 26 & 26 \\
\hline \multirow[t]{2}{*}{15} & Girls & 16 & 15 & 17 & 16 & 18 & 17 & 20 & 20 & 22 & 22 & 24 & 26 & 27 & 28 \\
\hline & Boys & 15 & 15 & 16 & 15 & 17 & 17 & 19 & 18 & 21 & 21 & 23 & 25 & 26 & 27 \\
\hline \multirow[t]{2}{*}{16} & Girls & 16 & 16 & 17 & 16 & 18 & 18 & 20 & 20 & 22 & 23 & 24 & 27 & 27 & 29 \\
\hline & Boys & 16 & 15 & 17 & 16 & 18 & 17 & 20 & 19 & 22 & 21 & 24 & 25 & 26 & 28 \\
\hline \multirow[t]{2}{*}{17} & Girls & 17 & 16 & 17 & 17 & 19 & 18 & 21 & 21 & 23 & 24 & 24 & 26 & 27 & 29 \\
\hline & Boys & 16 & 16 & 17 & 17 & 18 & 18 & 20 & 20 & 23 & 23 & 24 & 27 & 27 & 30 \\
\hline \multirow[t]{2}{*}{18} & Girls & 17 & 17 & 17 & 17 & 19 & 19 & 21 & 21 & 23 & 23 & 24 & 25 & 28 & 28 \\
\hline & Boys & 16 & 16 & 17 & 17 & 19 & 19 & 21 & 21 & 23 & 23 & 25 & 27 & 28 & 30 \\
\hline
\end{tabular}

BMI - body mass index, CASPIAN - Childhood and Adolescence Surveillance and Preventlon of Adult Noncommunicable disease

overweight is increasing, i.e. such populations face the double burden of malnutrition [15].

It seems that the double burden of nutritional disorders is present in all age groups of Iranian children and adolescents. In the developing world, the pattern of nutrition is unique and leads to the coexistence of underweight and overweight $[35,36]$. Comparing rural and urban areas in this study showed that underweight is significantly higher in rural than in urban children and adolescents (22.1\% vs. $15.8 \%)$. The higher level of underweight children in rural areas may be secondary to under-nutrition and the higher level of overweight and obese children in urban areas may be indicative of their inadequate physical activity $[37,38]$ and unhealthy lifestyle $[22,39,40]$. Before a nutritional transition, overweight was concentrated in high socioeconomic status (SES) groups and underweight in low-SES groups, but after the transition, overweight also shifted to the low-SES groups. Thus, low-SES groups face the double burden of nutritional disorders [41]. In recent years, in some industrialized countries such as Italy
[18], Spain [17] and France [19], the prevalence of underweight is increasing. This might be due to more concern about body image among children and adolescents, consuming foods with low nutritional value, more participation in physical activity programs and more education about the risks of obesity for health.

The $5^{\text {th }}$ and $50^{\text {th }}$ percentile curves for WC in our study are similar to Turkish ones [42], but the $95^{\text {th }}$ percentile curve is considerably higher than the Turkish curve. The $5^{\text {th }}, 50^{\text {th }}$ and $95^{\text {th }}$ standard curves of boys in the current study are similar to the findings of the survey on the percentiles of WC among Pakistani primary school children, aged 1012 years. Among girls, the $5^{\text {th }}$ percentile curves of WC of Iranian children are similar to the Pakistani data, but the $50^{\text {th }}$ and $95^{\text {th }}$ curves of Pakistani girls are higher than Iranian girls [43].

Comparison of the present study with the study conducted in Honk Kong [28] shows that the $5^{\text {th }}$, $50^{\text {th }}$ and $95^{\text {th }}$ WC percentile curves of Iranian children are higher than Hong Kong Chinese children. Comparison of WC data from the current study 
Table IV. Age- and gender-specific mean of WC and BMI: comparison of CASPIAN-I and CASPIAN-III results

\begin{tabular}{|c|c|c|c|c|c|c|c|}
\hline \multirow{3}{*}{$\begin{array}{l}\text { Age } \\
\text { [years] }\end{array}$} & \multirow{3}{*}{$\begin{array}{l}\text { Gender } \\
N(\mathrm{I} / \mathrm{III})\end{array}$} & \multicolumn{3}{|c|}{ BMI } & \multicolumn{3}{|c|}{ WC } \\
\hline & & \multicolumn{2}{|c|}{ CASPIAN } & \multirow{2}{*}{$\begin{array}{l}\text { Value } \\
\text { of } p\end{array}$} & \multicolumn{2}{|c|}{ CASPIAN } & \multirow{2}{*}{$\begin{array}{c}\text { Value } \\
\text { of } p\end{array}$} \\
\hline & & I & III & & I & III & \\
\hline \multirow[t]{2}{*}{10} & Girls (791/57) & $16.83 \pm 3.23$ & $16.86 \pm 3.84$ & 0.95 & $60.66 \pm 8.91$ & $58.05 \pm 6.23$ & 0.03 \\
\hline & Boys (842/31) & $16.87 \pm 3.52$ & $16.44 \pm 2.57$ & 0.50 & $60.58 \pm 8.95$ & $59.00 \pm 6.69$ & 0.33 \\
\hline \multirow[t]{2}{*}{11} & Girls (812/197) & $17.58 \pm 3.48$ & $16.68 \pm 3.00$ & $<0.001$ & $62.82 \pm 9.48$ & $60.79 \pm 9.47$ & 0.007 \\
\hline & Boys $(933 / 161)$ & $17.33 \pm 3.41$ & $16.88 \pm 2.92$ & 0.11 & $63.09 \pm 9.68$ & $61.10 \pm 7.93$ & 0.01 \\
\hline \multirow[t]{2}{*}{12} & Girls (1069/372) & $18.72 \pm 3.75$ & $17.79 \pm 3.75$ & $<0.001$ & $65.12 \pm 10.92$ & $62.63 \pm 9.16$ & $<0.001$ \\
\hline & Boys $(1031 / 401)$ & $18.21 \pm 3.78$ & $17.55 \pm 3.47$ & 0.002 & $65.47 \pm 10.13$ & $63.91 \pm 9.57$ & 0.007 \\
\hline \multirow[t]{2}{*}{13} & Girls (899/307) & $19.31 \pm 3.59$ & $18.56 \pm 3.91$ & 0.002 & $66.22 \pm 10.80$ & $64.75 \pm 8.60$ & 0.31 \\
\hline & Boys $(1030 / 348)$ & $18.35 \pm 3.43$ & $18.10 \pm 4.00$ & 0.26 & $66.75 \pm 10.36$ & $66.44 \pm 11.80$ & 0.64 \\
\hline \multirow[t]{2}{*}{14} & Girls (1027/284) & $20.17 \pm 3.57$ & $19.58 \pm 3.98$ & 0.02 & $68.12 \pm 9.80$ & $67.41 \pm 8.82$ & 0.27 \\
\hline & Boys $(1221 / 300)$ & $19.38 \pm 3.95$ & $18.49 \pm 3.61$ & $<0.001$ & $69.22 \pm 10.38$ & $67.54 \pm 9.30$ & 0.01 \\
\hline \multirow[t]{2}{*}{15} & Girls (1042/376) & $20.32 \pm 3.52$ & $20.33 \pm 4.14$ & 0.95 & $68.77 \pm 8.84$ & $69.26 \pm 9.02$ & 0.36 \\
\hline & Boys $(1063 / 325)$ & $19.71 \pm 3.48$ & $19.24 \pm 3.85$ & 0.03 & $69.67 \pm 11.15$ & $70.06 \pm 10.57$ & 0.57 \\
\hline \multirow[t]{2}{*}{16} & Girls (1029/283) & $20.65 \pm 3.68$ & $20.98 \pm 3.92$ & 0.18 & $68.79 \pm 8.29$ & $71.05 \pm 9.33$ & $<0.001$ \\
\hline & Boys (980/293) & $20.41 \pm 3.31$ & $19.88 \pm 3.82$ & 0.02 & $71.38 \pm 10.64$ & $72.23 \pm 10.46$ & 0.22 \\
\hline \multirow[t]{2}{*}{17} & Girls (660/323) & $21.01 \pm 3.27$ & $21.36 \pm 3.70$ & 0.13 & $69.54 \pm 7.67$ & $71.40 \pm 9.81$ & 0.001 \\
\hline & Boys (729/385) & $20.93 \pm 3.56$ & $20.94 \pm 4.14$ & 0.96 & $71.94 \pm 11.78$ & $74.93 \pm 11.01$ & $<0.001$ \\
\hline \multirow[t]{2}{*}{18} & Girls (290/338) & $21.22 \pm 3.40$ & $21.26 \pm 3.62$ & 0.88 & $71.02 \pm 8.76$ & $70.94 \pm 7.97$ & 0.90 \\
\hline & Boys (299/316) & $21.22 \pm 3.42$ & $21.52 \pm 4.03$ & 0.32 & $72.11 \pm 11.36$ & $76.97 \pm 10.75$ & $<0.001$ \\
\hline
\end{tabular}

Data are mean $\pm S D, B M I-$ body mass index, $W C$ - waist circumference

with the British study [27] showed that the $5^{\text {th }}$ and $50^{\text {th }}$ curve of both studies is in close agreement, but the $95^{\text {th }}$ percentile curve of Iranian children is higher than the British ones.

Study limitations and strengths: Because of the large sample size studied, we could not determine the pubertal status of participants. Moreover, as a school-based surveillance program, we could not gather detailed information on social determinants of health of participants and similar information related to epidemiological transition at the population level. The strength of the study is studying a large sample size at the national level, considering both urban and rural areas and using the same protocol in different phases of the study.

In conclusion, this study revealed an increase in the dual burden of weight in recent years among Iranian children and adolescents. It may be related to epidemiologic and nutrition transition resulting in rapid changes in lifestyle habits. This finding is an important issue for policy-makers for interventional preventive programs. This study high- lights the importance of regular monitoring of the growth pattern of children and adolescents, and presenting them to stakeholders and policy-makers for implementation of national health policies.

References

1. Dehghan M, Akhtar-Danesh N, Merchant AT. Childhood obesity: prevalence and prevention. Nutr J 2005; 4: 24-32.

2. Onis M, Blossner M. The World Health Organization Global Database on child growth and malnutrition: methodology and applications. Int J Epidemiol 2003; 32: 518-26.

3. World Health Organization. Global strategy for noncommunacable disease prevention and control. Geneva, Switzerland: World Health Organization 1997 (publication no. WHO/ NCD/ GS/ 97.1).

4. Withaker RC, Wright JA, Pepe MS, et al. Predicting obesity in young adulthood from childhood and parental obesity. N Engl J Med 1997; 337: 869-73.

5. Saha AK, Sarkar N, Chatteriee T. Health consequences of childhood obesity. Indian J Pediatr 2011; 78: 1349-55.

6. Tentolouris N, Andrianakos A, Karanikolas G, et al. Type 2 diabetes mellitus is associated with obesity, smoking and low socioeconomic status in large and representative samples of rural, urban, and suburban adult Greek populations. Hormones (Athens) 2012; 11: 458-67. 
7. Sandad M, Gharib A. Evaluation of microalbuminuria in obese children and it's relation to metabolic syndrome. Pediatr Nephrol 2011; 26: 2193-9.

8. Choy CS, Chan WY, Chen TL, Shih CC, Wu LC, Liao CC. Waist circumference and risks of elevated blood pressure in children: a cross-sectional study. BMC Public Health 2011; 11: 613.

9. Robinson WR, Poole C, Godley PA. Systematic review of prostate cancer's association with body size in childhood and young adulthood. Cancers Causes Control 2008; 19: 793-803.

10. Taylor RW, Jones IE, Williams SM, Goulding A. Evaluation of waist circumference, waist to hip ratio, and the coincity index as screening tools for high trunk fat mass, as measured by dual-energy X-ray absorptiometry, in children aged 3-19 years. Am J Clin Nutr 2000; 72: 490-5.

11. Savva SC, Tornaritis M, Savva ME, et al. Waist circumference and waist to hip ratio are better predictors of cardiovascular disease risk factors in children than body mass index. Int J Obes Relat Metab Disord 2000; 24: 1453-8.

12. Kissebah $\mathrm{AH}$, Videlingum N, Murray R, et al. Relation of body fat distribution to metabolic complications of obesity. J Clin Endocrinol Metab 1982; 52: 254-63.

13. Katzmark RT, Srinivasan SR, Chen W, Malina RM, Bouchard C, Berenson GS. Body mass index,waist circumference and clustering of cardiovascular disease risk factors in a biracial sample of children and adolescents Pediatrics 2004; 114: e198-205.

14. Jafar TH, Qadri Z, Islam M, Hatcher J, Bhutta ZA, Chaturvedi N. Rise in childhood obesity with persistently high rates of undernutrition among urban-school aged Indo-Asian children. Arch Dis Child 2008; 93: 373-8.

15. Ke-You G, Da-Wei F. The magnitude and trends of under- and over-nutrition in Asian countries. Biomed Environ Sd 2001; 14: 53-60.

16. Ha Do TP, Feskens JM, Deurenberg P, Mai LB, Khan NC, Kok FJ. Nationwide shifts in the double burden of overweight and underweight in Vietnamese adults in 2000 and 2005: two national nutrition surveys 2011. BMC Public Health 2011; 11: 62

17. Vizcaino VM, Lopez MS, Martinez PM, et al. Trends in excess weight and thinness among Spanish schoolchildren in the period 1992-2004: the Cuenca study. Public Health Nutrition 2008; 12: 1015-8.

18. Lazzeri G, Rossi S, Pammolli A, Pilato V, Pozzi T, Giacchi MV. Underweight and overweight among children and adolescents in Tuscany(Italy). Prevalence and shortterm trend. J Prevent Med Hyg 2008; 49: 13-21.

19. Rolland-Cachera MF, Castetbon K, Arnault N, et al. Body mass index in 7-9-y-old French children: frequency of obesity, overweight and thinness. Int J Obesity 2002; 26: 1610-6.

20. Alavian SM, Motlagh ME, Ardalan G, Motaghian M, Davarpanah $\mathrm{AH}$, Kelishadi R. Hypertriglyceridemic waist phenotype and associated lifestyle factors in a national population of youths: CASPIAN Study. J Trop Pedatr 2008; 54: 169-77.

21. Kelishadi R, Ardalan G, Gheiratmand R, et al. Thinness, overweight and obesity in a national sample of Iranian children and adolescents: CASPIAN study. Child Care Health Development 2008; 34: 44-54.

22. Kelishadi R, Ardalan G, Gheiratmand R, et al. Association of national sample of Iranian children and adolescents:
CASPIAN study. Bulletin of the World Health Organization 2007; 85: 19-26.

23. Kelishadi R, Heshmat R, Motlagh ME, et al. Methodology and early findings of the third survey of CASPIAN study: a national school-based surveillance of students' high risk behaviors. Int J Prev Med 2012; 3: 394-401.

24. Kelishadi R, Gouya MM, Ardalan G, et al. First reference curves of waist and hip circumferences in an Asian population of youths: CASPIAN study. J Trop Pediatr 2007; 53: 158164.

25. http://www.who.int/childgrowth/en/.

26. Stepwise approach to surveillance (STEPS) [article online], 2004. Available from http://www.who.int/chp/ steps/en.

27. Mc Carthy HD, Jarret KV, Crawley HF. The development of waist circumference percentiles in British children aged 5-15.9 y. Eur J Clin Nutrition 2001; 55: 902-7.

28. Sung RYT, So HK, Choi KC, et al. Waist circumference and waist-to-height ratio of Hong Kong Chinese children. BMC Public Health 2008; 8: 324.

29. Julia $M$, van Weissenbruch MM, Prawirohartono EP, Sur juno A, Delemarre-van de Waal HA. Tracking for underweight, overweight and obesity from childhood to adolescence: a 5-year follow-up study in urban Indonesian children. Hormone Res 2008; 69: 301-6.

30. Custodio E, Descalzo MA, Roche J, et al. The economic and nutrition transition in Equatorial Guinea coincided with a double burden of over- and under- nutrition. Economics and Human Biology 2010; 8: 80-7.

31. Motlagh ME, Kelishadi R, Amirkhani MA, et al. Double burden of nutritional disorders in young Iranian children: finding of a nationwide screening survey. Public Health Nutrition 2011; 14: 605-10.

32. Mehrkash M, Kelishadi R, Mohammadian S, et al. Obesity and metabolic syndrome among a representative sample of Iranian adolescents. Southeast Asian J Trop Med Public Health 2012; 43: 756-63.

33. Wang Y, Monteiro C, Popkin BM. Trends of obesity and underweight in older children and adolescents in the United States, Brazil, China and Russia. Am J Clin Nutrition 2002; 75: 971-7

34. Kouda K, Harunobu N, Nishio N, Fujita Y, Takeuchi H, Iki M. Trends in body mass index, blood pressure, and serum lipids in Japanese children: Iwata population-based annual screening (1993-2008). J Epidemiol 2010; 20: 212-8.

35. Delisle HF. Poverty: the double burden of malnutrition in mothers and the intergenerational impact. Annals of the New York Academy of Sciences 2008; 1136: 172-84.

36. Popkin BM. The nutrition transition: an overview of world patterns of change. Nutrition Rev 2004; 62: S140-3.

37. Rey-Lopez JP, Vicente-Rodriguez G, Biosca M, Moreno LA. Sedentary behavior and obesity development in children and adolescents. Nutrition Metabol Cardiovasc Dis 2008; 18: 242-51

38. Tremblay MS, Willms JD. Is the Canadian childhood obesity epidemic related to physical inactivity? Int J Obes Relat Disord 2003; 27: 1100-5.

39. Spence JC, Carson V, Casey L, Boule N. Examining behavioral susceptibility among Canadian pre-school children: the role of eating behaviors. Int J Pediatr Obes 2011; 6: e501-11.

40. Guran T, Bereket A. International epidemic of childhood obesity and television viewing. Minerca Pediatrica 2011; 63: 483-9. 
41. Monterio CA, Moura EC, Conde WL, Popkin BM. Socioeconomic status and obesity in adult populations of developing countries: a review. Bulletin of the World Health Organization 2004; 82: 940-6.

42. Hatipoglu N, Ozturk A, Mazicioglu MM, Kurtoglu S, Seyhan S, Lokoglu F. Waist circumference percentiles for 7- to 17-year-old Turkish children and adolescents. Eur J Pediatr 2008; 167: 383-9.

43. Moshtaq MU, Gull S, Abdullah HM, Shahid U, Shad MA, Akram J. Waist circumference, waist-hip ratio, and waist-height ratio percentiles and central obesity among Pakistani children aged five to twelve years. BMC Pediatrics 2011; 11: 105. 